\title{
A GENEALOGIA DA LÓGICA \\ E A FILOSOFIA DA LEBENSWELT
}

Carlos Morujão

Universidade Católica Portuguesa

\section{A fundação fenomenológica da lógica}

\subsection{Os textos}

Esta conferência, quaisquer que possam ser as suas imperfeições ou os seus erros, parte de uma convicção que o avanço dos meus estudos husserlianos apenas tem fortalecido: a convicção de que, se separarmos da fenomenologia a sua problemática lógica, não só não aproximamos a fenomenologia da existência ou da vida, como também lhe roubamos uma bọa parte do seu rigor. Esta conferência será, então, em primeiro lugar, um comentário aos capítulos $3 .^{\circ}$ e $4 .^{\circ}$ da Segunda Secção de Formale und transzendentale Logik ${ }^{1}$ e à obra Experiência e Juizo, publicada por Ludwig Landgrebe em 1939. (Hoje em dia será sempre necessário confrontar o texto de Experiência e Juizo com os manuscritos publicados no volume XI da Husserliana, com o título de Analysen zur Passiven Synthesis, e no volume XXXI, com o.título de Aktive Synthesen. Estes últimos constituem a parte final, e não mais retomada, de uma lição de Husserl de 1920-21 sobre "Lógica Transcendental", cuja parte inicial - o conteúdo do mencionado volume XI da Husserliana - foi retomada em anos subsequentes.) Para o tema desta conferência, ter-se-ão ainda em conta a 2. ${ }^{a}$ Parte da Krisis der europäischen Wissenschaften, diversos Apêndices a esta obra a que se fará referência no decurso da exposição e a Introdução do próprio Landgrebe a Experiência e Juizo, ou seja, os $\S \S 1$ a 14.

1 Referir-nos-emos muitas vezes a esta obra pela sigla FTL; as referências à paginação reenviam para o vol. XVII da Husserliana, indicada pela abreviatura Hua. 
A opção por Experiência e Juizo e não pelo texto reproduzido nos dois mencionados volumes da Husserliana deve-se, em primeiro lugar, a razões de ordem prática: a edição dos manuscritos, preparada por Ludwig Landgrebe é mais facilmente manejável e também mais acessível do ponto de vista económico. Além disso, o facto de os editores da Husserliana não aceitarem o texto, cuja versão final se deve a Landgrebe, como texto husserliano autêntico, tendo em conta o carácter atribulado da sua Entstehungsgeschichte, não nos parece uma decisão totalmente pacífica. Ainda hoje, como se sabe, muita da investigação em torno da última fase do pensamento de Husserl se continua a servir do texto publicado por Landgrebe. Como é igualmente sabido, o modo de Husserl trabalhar com os seus próprios manuscritos implicava o recurso à colaboração dos seus assistentes, que eram quem, muitas vezes, se encarregava da preparação do texto para a publicação final. Assim aconteceu com o trabalho de Edith Stein e de Martin Heidegger relativamente às Vorlesungen über die innere Zeitbewusstsein, publicadas por este último em 1928, e ao trabalho do próprio Landgrebe relativamente a Formale und transzendentale Logik, no ano seguinte. ${ }^{2}$ Aliás, as Analysen zur passiven Syntnesis - título que, convém recordá-lo, não é de Husserl, mas sim dos editores da Husserliana -, sejam quais forem os méritos (e.são muitos) que lhe devam ser atribuídas, não se limitam a restituir o texto das lições de Husserl, pois procedem a um "arranjo" dos textos dos manuscritos F I 37 e F I 38 que não corresponde, na sua forma final, à sequência que lhes fora dada por Husserl; acontece até que uma parte de F I 37 foi deslocada para o volume XVII da Husserliana, constituindo um dos Apêndice a Formale und transzendentale Logik.

Recordemos ainda algumas das circunstâncias que rodearam a redação de Experiência e Juizo. Em carta de 19 de Março de 1930, dirigida a Roman Ingarden, ${ }^{3}$ Husserl menciona o projeto de conclusão de um 2 tes logisches Buch ("2.. livro de lógica"; o primeiro, recordemo-lo, fora Formale und transzendentale Logik, publicado no ano anterior) e em cuja redação se encontrava já empenhado, com a colaboração de Landgrebe. Uma primeira hipótese de título - Logische Studien - chegou mesmo a ser considerada, para, pouco depois, ser recusàda pelo próprio Husserl. ${ }^{4}$ Este livro, porém, ver-se-ia retardado, na sua forma final, pelo projeto da edição alemã das Cartesianische Meditationen, a qual, como se sabe, só verá a luz muito mais tarde, em 1950, como primeiro volume da Husserliana. ( $\mathrm{O}$ afastamento de Landgrebe, motivado pelos traba-

2 Sobre este assunto, cf. as palavras de Husserl no final da "Introdução" a FTL, Hua XVII, 21.

${ }^{3}$ Cf. Roman Ingarden (hrsg.), Briefe an Roman Ingarden, Den Haag: Martinus Nijhoff, 1968, p. 58 . Ver, igualmente, a nota 47 de Ingarden, pp. 164-165.

${ }^{4}$ Cf. a carta de Husserl a Ingarden de 21.12.1930; in Briefe an Roman Ingarden, ed. cit., p. 62. 
lhos preparatórios da sua tese de Habilitação, explicará também; em parte, o atraso.) Ora o tal segundo livro a que Husserl se refere na mencionada carta mais não é do que o trabalho que Landgrebe publicará em 1939 com o título de Experiência e Juízo. Apesar do afastamento físico de Landgrebe, que desde 1935 ocupava um lugar de Privat-Dozent na Universidade de Praga, o trabalho de colaboração com Husserl continuou, quer em curtas estadias de Landgrebe em Freiburg, quer por via epistolar. Por todos estes motivos, tivesse Husserl morrido um pouco mais tarde e cremos que ninguém contestaria hoje que Experiência e Juizo (com a exceção, obviamente, dos 14 parágrafos da "Introdução") fosse uma obra sua.

\subsubsection{O plano da exposição}

A nossa exposição comportará três partes. Numa primeira parte procuraremos enunciar as principais teses de Husserl sobre a lógica formal, os seus níveis, a sua relação com a matemática formal e a ontologia formal. Tratar-se-á, por conseguinte, de proceder a uma delimitação do âmbito do domínio lógico, na sua autonomia. Partiremos da apresentação que Husserl faz deste assunto nas suas obras de maturidade, em particular em FTL. Numa segunda parte, procuraremos mostrar de que forma, para a fenomenologia, a análise das configurações lógicas objetivas deve ser completada por uma análise das realizações subjetivas nas quais têm a sua génese. Por outras palavras, tratar-se-á, agora, de fundar a referida autonomia na natureza própria da razão lógica. Por fim, na terceira e última parte, entraremos diretamente no tema enunciado no título desta comunicação.

Sobre esta terceira parte, necessitamos de fornecer alguns esclarecimentos prévios, pois, como facilmente se depreende, estudar o enraizamento da atividade lógico-categorial no plano antepredicativo da experiência passiva não é exatamente o mesmo que mostrar que todas as idealizações de nível superior, ou seja, quer os produtos da atividade científica explicitamente orientada por um interesse de conhecimento, quer as formações da cultura em sentido lato, se enraízam também no mundo da experiência imediata, que é o nosso mundo da vida, com as suas sedimentações, os seus estratos de atividade cultural passada e o conjunto dos seus hábitos. Ou seja, à primeira vista, o título da nossa comunicação reúne duas problemáticas que, não só se não identificam totalmente, como também podem ser investigadas em separado. Além disso, entre Experiência e Juizo e a Krisis parece-nos existir uma diferença de orientação relativamente ao modo de realização do programa fenomenológico que não facilita, antes dificulta, a aproximação entre estas duas obras. Na primeira, vemos a fenomenologia ascender da consciência constituinte, que opera no plano percetivo, em direção às objetividades já constituídas da lógica formal; 
na segunda - neste aspeto muito mais próxima do procedimento efetivo de Formale und transzendentale Logik -, procede-se por análise intencional do estado atual das realizações da ciência, incluindo nelas a lógica formal, para, no decurso do processo da sua fundação na experiência originária da subjetividade transcendental, proceder à demonstração de duas coisas: 1) que o mundo da ciência é, como the chama Husserl, uma substrução no mundo da vida e não o mundo verdadeiramente real; 2) que existe uma inadequação entre as realizações efetivas da ciência ocidental e o ideal de ciência. Desta forma, se na démarche husserliana em Experiência e Juizo - que poderíamos classificar como progressiva ou ascendente - seria deslocada qualquer crítica da lógica, ao invés, na Krisis e, por maioria de razão, em Formale und transzendentale Logik, em que a démarche tem um carácter regressivo, a crítica, quer da lógica -formal (nos seus pressupostos idealizantes), quer da matemática formal, quer ainda da ontologia formal nela fundada, constitui um momento obrigatório.

Voltemos, no entanto, à questão de há pouco, formulada agora de modo um pouco diferente: será legítimo identificar a determinação do momento da recetividade - enquanto desencadeadora do processo de objetivação e, por isso mesmo, ponto de partida da genealogia da lógica - com a filosofia do mundo da vida? É compreensível que uma abordagem comparativa dos textos de Husserl sobre estas duas problemáticas possa causar alguma perplexidade e que uma forte objeção.pudesse vir a ser colocada à nossa tentativa de sobreposição das duas: uma objeção que partiria do reconhecimento, não de que existam dois tipos diferentes de "mundo da vida", naturalmente, mas sim de que, na sua análise, podem operar dois tipos de interesse distintos. A problemática genealógica parece ocupar-se exclusivamente com a história da constituição do objeto, desde o momento da captação dos dados hiléticos até à sua integração na estrutura categorial. Por outras palavras, a objeção que se poderia fazer partiria da constatação de que se trata, num caso, de um problema de ordem estritamente epistemológica (que seria o da genealogia) e, no outro, de um problema de ordem da filosofia da cultura (e que seria o da filosofia da Lebenswelt que é desenvolvida na Krisis).

Não obstante, e reconhecendo que os interesses podem não se sobrepor completamente, começámos por perguntar a nós próprios se algum conceito husserliano, que se encontrasse presente nas duas problemáticas, nos daria a possibilidade de proceder a uma aproximação entre elas. Julgamos tê-lo encontrado no conceito de tipo (e suas variações: tipificação, tipicalidade, etc.). Com efeito, Husserl usa-o tanto em Experiência e Juizo como na Krisis, embora com pequenas variações quanto ao significado. Na primeira destas duas obras, ele refere-se ao objeto que, uma vez constituído numa experiência e transformado em posse latente habitual, pode ser despertado por uma experiência presente de um objeto semelhante, ou que, no caso de o interesse 
temático vir a ser novamente ạtivado, pode aparecer numa cạptação mais abrangente, em unidade com as captações anteriores; na segunda, ele refere-se à forma indecisa, mas aproximada, de um objeto, comportando gradações na sua perfeição, mas servindo propósitos de ordem prática. Trata-se, contudo, num e noutro caso, da forma predominante de utilizar este conceito em cada uma das duas mencionadas obras, o que não exclui que algumas ocorrências da primeira forma se possam encontrar na Krisis, nem que algumas ocorrências da segunda forma se possam encontrar também em Experiência e Juizo. O que nos propomos mostrar é que, tanto no caso da primeira forma como no da segunda, a formação do tipo só é possível se considerarmos que a experiência é; em primeiro lugar, a experiência de objetos individuais, e que só na sua base se podem vir a constituir as objetividades lógico-matemáticas e os pressupostos idealizantes de que tanto a lógica como a matemática fazem uso.

\subsection{A distinção entre a problemática genealógica e a problemática da origem}

No $\S 36$ da Krisis, a propósito do problema de como pode o mundo-da-vida tornar-se tema de uma ciência, Husserl considera que a lógica formal é vítima de uma ingenuidade: ela não fundamenta a sua pretensão em ser uma ciência a priori universal para todas as ciências e supõe, ingenuamente, que a evidência das suaș demonstrações a dispensa de qualquer fundamentação. Ora a lógica, diz Husserl, não se funda a si mesma de acordo com procedimentos lógicos, mas sim num a priori universal pré-lógico. ${ }^{5}$ Contudo, este universal pré-lógico não é, simplesmente, o mundo da vida quotidiana; neste, as atividades lógicas superiores, bem como outro tipo de idealizações (ideias científicas, convicções políticas ou religiosas, etc.), encontram-se já depositadas de acordo com um processo que Husserl qualifica como de "sedimentação". Por outro lado, o universal pré-lógico não é um mundo estranho à lógica em sentido lato. Aliás, nos estudos sobre a álgebra da lógica, dos anos 90 do século XIX, e em Philosophie der Arithmetik, Husserl defendia que, tal como nas operações lógicas, realizadas com o auxílio de símbolos algébricos, permanecem ainda estruturas intuitivas elementares, também na consciência natural existem ideias lógicas e matemáticas. ${ }^{6}$ Esta relação de fundação é uma relação complicada, que tentaremos esclarecer ao longo desta comunicação.

\footnotetext{
${ }^{5}$ Krisis, § 36, Hua VI, 144.

${ }^{6}$ Ernst Wolfgang Orth, Edmund Husserls $>$ Krisis der europäischen Wissenschaften und die transzendentale Phänomenologie<, Darmstadt: WissenschaFTLiche Buchgesellschaft, 1999, p. 131.
} 
Deparámos, porém, ao enunciar esta dificuldade, com a dificuldade fundamental do projeto que pretendemos levar a cạbo. A nossa exposição deverá evitar dois perigos, que, no fundo, relevam de duas questões não inteiramente resolvidas, ao que pensamos, pelo próprio Husserl. Em primeiro lugar, devemos evitar estabelecer uma continuidade tal entre o plano antepredicativo do mundo da vida e o das formações lógicas e gnosiológicas de nível superior que se viesse a traduzir numą subrepção ilegítima do plano lógico em níveis onde, supostamente, ele teria de estar ausente. Mas, em segundo lugar, deveremos evitar atribuir ao primeiro daqueles dois planos - ou seja, o antepredicativo - um nível tal de autenticidade e de espessura ontológica que transforme o segundo numa mera ilusão, ou em construção arbitrária do espírito humano.

O projeto fenomenológico de "ir às próprias coisas" implica o reconhecimento de que as coisas - que, no nosso caso, não são objetos reais, mas sim objetividades da lógica formal -, tal como habitualmente as experimentamos, são já, muitas vezes, complexos de sentido resultantes de uma atividade intencional constituinte. Um exemplo simples ajudar-nos-á a compreender esta situação: a significação de um predicado nominalizado (para simplificar: um adjetivo transformado em substantivo) que pode figurar como sujeito de um juízo - por exemplo: "o vermelho deste telhado" -, reenvia para o significado do predicado original, que, no nosso exemplo, poderia aparecer num juízo como: "este telhado é vermelho". Nada impede, obviamente, que, do ponto de vista empírico-psicológico, alguém possa ter tomado conhecimento da significação nominalizada antes da significação do adjetivo que lhe corresponde e que a funda. Mas, como veremos no decurso desta comunicação, o objetivo da genealogia da lógica não é apenas o de reconduzir as formações sintaticamente mais complexas, como sejam as que resultam da nominalização, às formações mais simples. Husserl irá conduzir o seu leitor - seja ele lógico ou matemático, trabalhando na atitude natural - pelo interior do âmbito da totalidade da problemática lógica, até emergir nele a convicção de que necessita de uma compreensão transcendental da natureza das realizações subjetivas da consciência que constituíram as objetividades (Gegenstänlichkeiten) lógicas, incluindo a matemática formal e a ontologia formal. Poderá, alguma vez, esta convicção emergir nele? Não estamos ainda em condições de apresentar os termos da resposta de Husserl para esta questão. Precisamos, primeiro, de percorrer aquela totalidade da problemática lógica que acabei de referir, ou seja, toda a $1 .^{a}$ Secção de Formale und transzendentale Logik. É o que iremos fazer já na próxima alínea desta comunicação. 


\subsection{O conceito de lei em Formale und transzendentale Logik}

Em 1929, Formale und transzendentale Logik propõe-se, de acordo com o anunciado no seu $\S 8$, estabelecer as leis essenciais das realizações (Leistungen) subjetivas em que se constituem as configurações objetivas da lógica e da matemática formais: ${ }^{7}$ ou seja, os juízos, as categorias, os esquemas de inferência, postos à disposição do lógico e do matemático como Habitualitäten e reconhecidos como idênticos em operações sempre diversas.

Por um lado, Husserl retoma um programa de trabalhos já anunciado em 1913 em Ideias-I (em particular nos $\S \S 92$ e 93), a saber, o estabelecimento de uma correlação a priori universal entre objetos pensados e realizações constituintes da consciência: afirmava, com efeito, nesta obra: "Que nenhum momento noético existe sem um momento noemático que especificamente lhe corresponda, tal é o teor de uma lei essencial que se verifica por toda a parte". ${ }^{2}$ Por outro lado, Husserl direciona esse trabalho no sentido de concluir os seus estudos lógicos iniciados na década de 90 do século XIX: tais estudos levados ao seu termo aparecem consignados na expressão "lógica transcendental", com o que Husserl designa a investigação do processo de engendramento daquelas leis essenciais mais acima referidas que presidem à constituição das objetividades lógico-matemáticas.

Um tal processo é, em larga medida, inconsciente, num sentido obviamente não psicanalítico do termo. Aquela intencionalidade em ato, ou operante, não constitui o tema próprio do trabalho do lógico. Ele vive o resultado das realizações subjetivas que geraram as objetividades lógicas, mas não o próprio processo dessa realização. Ėsta intencionalidade deverá ser "desenterrada" (enthüllt) pela reflexão fenomenológica e transformada em tema de análise. No trabalho normal dos lógicos ou dos matemáticos, como afirma Husserl, são objeto de uma consideração temática, unicamente, as configurações lógicas objetivas de que fazem uso e, mesmo assim, apenas momentaneamente, ou seja, durante o processo do seu uso.

A lógica formal tradicional é chamada, em $F T L$, apofântica formal e dividida em três níveis: a lógica das significações, a lógica da consequência e a lógica da verdade. Ao primeiro nível corresponde uma morfologia, ou doutrina das formas, do juízo, na mesma linha da "Gramática pura lógica", da 4. Investigação Lógica. O estabelecimento de uma doutrina das formas não impede juízos confusos (Verworren), nem garante que a passagem do confuso ao distinto equivalha à verdade do juízo; na realidade, e pensando que apo-

${ }^{7}$ FTL, $\S 8$, Hua XVII, 36 sgs.

${ }^{8}$ Ideen I, Hua III, 232. 
phansis se poderá traduzir por "asserção", ela determina apenas, para o juízo, aquela correção de ordem gramatical que possibilita que alguma coisa seja, de facto, asserida. Neste primeiro nivel, estabelece-se a necessidade de uma conformidade com as regras da sintaxe, evitando o que Husserl designa por Unsinn. Neste contexto, parece-nos que a tradução mais apropriada de Unsinn será "disparate", embora, traduzindo assim, se perca a referência ao Sinn - "sentido" -, que é um dos componentes da palavra alemã. Trata-se de um disparate, no sentido em que podemos dizer de alguém, que repete insistentemente uma frase como "o verde é ou", que está a dizer disparates. Exemplos deste género, que são dados pelo próprio Husserl, poderão contribuir para uma mais fácil compreensão desta problemática, mas convirá não esquecer que a morfologia pura das significações, que Husserl, no seguimento da 4. ${ }^{a}$ Investigação Lógica, aqui propõe deverá valer, em primeiro lugar, para as expressões formalizadas, quer dizer, para aquelas nas quais qualquer referência à matéria das significações está excluída. Assim, por exemplo, sendo "A e B" ou "se A, então $B$ " expressões com sentido, uma vez que os conectores de conjunção e de implicação material se encontram corretamente colocados, e isto seja o que for que A e B signifiquem, já "A não B" constitui um Unsinn. .

Para Husserl, quer (a) as diferentes categorias de significação (sujeito, predicado, proposição, etc.), quer (b) as regras sintáticas que determinam o modo de proceder à ligação daquelas categorias, quer (c) as regras gramaticais, constituem a condição para se operar a distinção entre uma frase com sentido e o puro e simples Unsinn. ${ }^{10}$ Estas distinções merecem-nos dois comentários. Primeiro: nesta investigação do nível 1, Husserl parece situar-se num âmbito onde não é ainda pertinente a distinção semântica entre o sentido e a referência de uma proposição. De facto, neste nível elementar da lógica trata-se simplesmente de determinar as leis que permitem que diferentes significações, pertencentes a diferentes categorias de significação, se podem reunir para dar origem a uma significação unitária, e não a um caos de significações. Nà frase "o verde é ou" encontramos diversas categorias de significação que não se podem ordenar daquela maneira; só por isso dizemos que a frase é incompreensível. Segundo comentário: relativamente à diferença, no interior deste nível 1, entre os níveis que identificámos como (b) e (c), este último determina todas as novas formas sintáticas que resultam da combinação das formas elementares; assim, por exemplo "S é p" - que constitui a forma fundamental do

9 Esta questão é sublinhada por Suzanne Bachelard, La Logique de Husserl, Paris: PUF, 1957, p. 56 , nota 2 .

${ }^{10}$ Cf. Suzanne Bachelard, "Logique husserlienne et sémantique", in Vérité et Vérification / Wahrheit und Verification, Akten des vierten internationales Kongresses für Phänomenologie, Den Haag: Martinus Nijhoff, 1974, pp. 117-131, p. 121. 
juízo categórico - pode ser transformado, por derivação, em, por exemplo, "Sp é verdade"."

O segundo nível respeita à lógica da consequência (ou da consistência). Este segundo nível determina as condições de possibilidade da verdade possível, ou seja, a compatibilidade das significações. É ele que constitui a novidade de FTL relativamente às Logische Untersuchungen,$_{,}^{12}$ na medida em que, nesta última obra, a lógica formal em sentido habitual incluía uma referência, em simultâneo, ao nível puramente formal (respeito pela não-contradição) e ao nível da verdade, que agora constitui um terceiro nível. ${ }^{13}$ O princípio deste segundo nível da lógica pode formular-se do seguinte modo: qualquer juízo contraditório é excluído pelo princípio que ele contradiz. ${ }^{14}$ Assim, por exemplo, a expressão "A e não A", admissivel de acordo com a doutrina das formas de significação, é agora excluída pelo princípio de não contradição.

A lógica do valor (ou da verdade), por fim, refere-se à determinação das condições para uma asserção ser verdadeira. O princípio que regula este nível da lógica é: se um juízo p é verdadeiro, o juízo p é falso. Os juízoṣ não são simplesmente pensados como meros juízos, mas sim enquanto se encontram orientados por um esforço que tem em vista o conhecimento, como visadas próprias de um sujeito orientado por um interesse de conhecimento, que tendem para um preenchimento intuitivo ${ }^{15}$ e que capazes de proporcionar o que Husserl chama a Selbsthabe des Vermeinten. Convirá deixar claro que a análise das condiçōes de possibilidade da verdade de um juízo não abandona o terreno de uma investi-

11 Cf. Rudolf Bernet / Iso Kern / Eduard Marbach, Edmund Husserl. Darstellung seines Denkens, Hamburg: Felix Meiner, 1989, p. 43. Seria em nosso entender possivel, o que aqui, todavia; não iremos fazer, mostrar a estreita relação entre estas transformações de que Husserl fala e as regras para a introdução e eliminação de conetores, nas modernas teorias do cálculo proposicional e do cálculo de predicados.

12 Sobre as razões da ausência deste segundo nivel nas Logische Untersuchungen pode consultar-se Suzanne Bachelard, La Logique de Husserl, ed. cit., p. 59.

${ }^{13}$ Cf. George Heffernan; Isagoge in die phänomenologische Apophantik, Dordrecht/Boston/ London: Kluwer Academic Press, 1989, pp. 68-69.

14 J. N. Mohanty, Edmund Husserl's Theory of Meaning, The Hague: Martinus Nijhoff, 1976, p. 125. Não iremos aqui fornecer uma explicação pormenorizada dos motivos que terão levado Husserl a autonomizar, como segundo nivel da apofântica formal, a lógica da consequência. Mas talvez se possa deixar apontado o papel desempenhado pela axiomatização de Hilbert, em que o princípio de não-contradição desempenha um papel fundamental. Segundo Hilbert, em qualquer sistema axiomático é necessário que as exigências colocadas pelos axiomas sejam satisfeitas pelos teoremas; ou seja, se um sistema qualquer de axiomas não conduz a nenhuma teoria, porque os teoremas que deles se.derivam são contraditórios, então será verdadeira a proposição que enunciar o carácter contraditório do próprio sistema. Cf. Paul Bernays, "La philosophie des mathématiques et la théorie de la démonstration de Hilbert", in Philosophie des Mathématiques (trad. de Hourya Benis Sinaceur), Paris: Vrin, 2003, pp. 41-82, p. 45.

${ }^{15}$ Cf. FTL, $\S 16$, p. 66; cf. igualmente $\S 19$, pp. 70-71. 
gação puramente formal. O predicado "ser verdadeiro" é atribuído aqui apenàs aos juízos enquanto juízos e não à relação dos juízos com os estadoṣ-de-coisas, relativamente aos quais, como é óbvio, uma investigação meramente formal não tem de se ocupar. ${ }^{16}$ Não parece fácil distinguir este terceiro nível do segundo, nem encontrar uma razão para uma distinção que, à primeira vista, é artificial. Husserl, contudo, insiste em que eles relevam de atitudes diferentes, motivadas por interesses teóricos distintos. No nível 2, o interesse dirige-se exclusivamente ao juizo, ao passo que no nível 3 se dirige à verdade possível do juízo.

Ora, no momento seguinte desta investigação - para nos situarmos: nos capítulos $3 .^{\circ}$ e $4 .^{\circ}$ da Segunda Secção de FTL - Husserl faz notar que esta argumentação, que visa explicitar a natureza dos princípios lógicos, utiliza já estes mesmos princípios, cuja validade está em causa. A peculiaridade desta situação poderia exprimir-se nos seguintes termos: uma teoria do juízo (a apofântica ou analítica formal) supõe já a validade do juízo enquanto configuração lógica objetiva, imprescindível no trabalho da ciência. Esta situação deriva do facto de, enquanto tal, o juízo "transcender" 17 os seus usos objectivos pelo lógico ou pelo matemático e constituir aquilo a que Husserl chama uma idealidade. A pergunta que está subjacente aos mencionados capítulos é a seguinte: poderá alguma vez esta configuração, ou idealidade, já constituída - uma vez que é usada -, ser analisada do ponto de vista da intencionalidade que a constituiu, de modo tal que, em resultado dessa análise, ela seja dada numa evidência adequada? A resposta de Husserl, ao que me parece, comportará dois tempos. Num primeiro tempo, a resposta é: não, mas, também, que não precisamos de estar alguma vez na posse dessa evidência. Se interpretámos bem, é o que nos é dito no $\S 73$ de FTL. E a resposta é "não" porque o movimento intencional de constituição nunca está terminado (embora este movimento, convém notá-lo, seja completamente diferente do procedimento "anónimo" de utilização reiterada de uma objetividade já constituída, como procede a atitude natural); mas ela é, também, "não precisamos dessa evidência", porque aquele mesmo movimento intencional está teleologicamente orientado para a constituição daquela objetividade ou configuração lógica, enquanto ideia em sentido kantiano.

Mas há, como dissemos, um segundo tempo na resposta husserliana. Neste segundo tempo, mais precisamente, nos $\S \S 82$ e segs. de FTL, somos, então, reconduzidos a uma teoria dos objetos individuais que clarifique todo o trabalho da lógica formal que se realiza a partir deles. Este é que é o projeto genealógico propriamente dito. Será apenas levado a cabo em Experiência e

${ }^{16}$ Suzanne Bachelard, La logique de Husserl, p. 72.

${ }^{17}$ Cf. André de Muralt, L'Idée de la Phénoménologie. L'Exemplarisme Husserlien. L'Exemplarisme Husserlien, Paris: PUF, 1958, p. 208. 
Juizo (ou nos textos das Analysen zur passiven Synthesis), acarretando, contudo, um alargamento da noção de juízo, de forma tal que este possa vir a coincidir (Husserl propõe-no expressamente no $\S 86$ de FTL) com o conceito humeano de crença. Para vermos como despontou a necessidade deste alargamento, começaremos por percorrer, em traços muito largos, os momentos fundamentais da obra de 1929.

Tanto Formale und transzendentale Logik, como ainda, sob uma outra forma, o"2.es logisches Buch", mencionado por Husserl na sua correspondência com Ingarden e que virá a ser, como já disse, Experiência e Juízo, procedem a um trabalho de fundamentação dos princípios lógicos mais gerais, a que Husserl chama, por vezes, pressupostos idealizantes (idealisierende Voraussetzungen) da lógica formal; trata-se daquelas configurações lógicas, ou estruturas categoriais, a que o lógico e o matemático recorrem, não porque lhes sejam atualmente evidentes, mas sim porque oferecem a possibilidade permanente de serem reativadas e identificadas como as mesmas, ou seja, na identidade do seu "ser em si" - Ansichsein, como Husserl diz -, que tem por base uma fundação originária - uma Urstiftung, como afirma em FTL - que não necessita de ser atualizada. ${ }^{18}$

O método husserliano de análise de todas estas questões em FTL é complexo e, à primeira vista, um pouco desorientador. Julgo que será oportuna uma pequena pausa, para recapitularmos, antes de prosseguir, as etapas que percorremos. Após uma investigação detalhada dos três mencionados níveis da lógica formal (no $1 .^{\circ}$ capítulo da $1 .^{a}$ Secção), ficamos a saber, no 2.. capítulo, que a matemática formal é também um nível da lógica; porém, tendo a matemática conduzido o processo de formalização a um ponto que a lógica clássica não alcançara, com ela, não só aprendemos a conhecer melhor o alcance e os limites da formalização - e, com isso, reconhecemos o carácter forçosamente incompleto das análises anteriormente levadas a cabo -, mas também que havendo estruturas formais comuns às duas disciplinas, uma ciência de âmbito mais alargado, uma mathesis universalis, as deverá englobar. Por fim, o 4. ${ }^{\circ}$ capítulo explica-nos que as categorias da matemática formal se aplicam aos objetos em geral, pelo que esta tem na ontologia formal o seu correlato necessário. Todavia, terminado o estudo da apofântica formal e da ontologia formal, Husserl considera que os problemas lógicos não se encontram ainda totalmente resolvidos. Não por faltar analisar ainda um qualquer nível da atividade lógica, mas sim porque ainda não se comprovou a legitimidade dos princípios lógicos por meio de uma investigação do solo experiencial (Erfahrungsboden) último onde eles se originam. 
Podemos, agora, retomar um conjunto de questões deixadas em suspenso mais atrás. Sentirão o lógico e o matemático a necessidade de realizar esta investigação? Terá a argumentação husserliana, finalmente, feito surgir neles a convicção da pertinência de uma investigação transcendental? Ser-lhes-á ela, sequer, de alguma utilidade? Desencadeará a lógica transcendental quaisquer efeitos sobre a lógica e a matemática formais? $\mathrm{E}$ onde situaremos o momento de passagem obrigatória para investigações de ordem transcendental, quer dizer, de ultrapassagem da "ingenuidade" com que o lógico e o matemático se servem das leis próprias dos seus domínios respetivos? É na Segunda Secção de FTL, como dissemos, consagrada à análise das realizações subjetivas que subjazem às objetividades lógico-formais, que encontraremos a resposta a estas perguntas. Em particular, nos $\S \S 74$ e 75 do Segundo Capítulo. Tal acontece quando, retomando as análises da Primeira Secção a propósito da apofântica formal, Husserl põe em evidência, já não mera a validade operativa das regras de inferência da pura lógica da consequência, mas sim as leis subjetivas de evidência que nos garantem que qualquer sujeito, orientado por um interesse de conhecimento, se encontrará sempre na efetuação das mesmas realizações subjetivas.

Assim, por exemplo, ao falar da série dos números inteiros, o matemático faz uso do processo de pensar que Husserl designa pela expressão "e assim sucessivamente"; a análise intencional tem a função de tornar explícito o pressuposto de validade de tal procedimento, mostrando de que forma ele serve de norma para a criação de uma objetividade, neste caso, a série infinita dos números inteiros. Esta objetividade constitui, nạ verdade, um pressuposto idealizante que é o correlato de um ato constituinte, na medida em que, de facto, a iteração do procedimento que constitui aquela série não pode ser prosseguida indefinidamente..$^{19} \mathrm{O}$ mesmo valerá para o princípio de não contradição. Objetivamente considerado, significa apenas que o valor de um juízo contraditório é excluído pelo valor do juízo que o contradiz. Subjetivamente, porém, ele significa que ninguém pode viver a evidência da clareza de um juízo e a sua contradição. ${ }^{20}$ Através do método das variações e atendendo apenas à forma sintática de um juízo - ou seja, independentemente da interpretação que possamos fazer das suas variáveis - verificamos a validade universal do princípio, sem que tal seja o resultado de uma impossibilidade empírico-psicológica nossa de o violarmos. O "não se poder julgar de outro modo" desempenha aqui um papel semelhante ao do "e assim sucessivamente" do exemplo anterior. ${ }^{21}$

${ }^{19}$ FTL, § 75, Hua XVII, 196; Suzanne Bachelard, op. cit., p. 192.

${ }^{20}$ Cf. Dieter Lohmar, op. cit., p. 145.

${ }^{21}$ FTL; $\S 75$, Hua XVII, 197. 
O lógico, o matemático, o homem de ciência em geral, vivem na convicção da evidência destes pressupostos idealizantes, de que constantemente fazem uso, sem nunca os tematizar, mas também sem disporem dos meios para o poder fazer. Não se trata, contudo, de pressupostos triviais, apesar de a sua formulação o poder dar a entender, pois deles depende a realização da ideia de ciência. Mas uma simples comprovação de ordem empírica, mesma acompanhada da presunção de necessidade e universalidade e comprovada pelo sucesso das suas realizações, não possui ainda o carácter $a$ priori que é exigido para a validade das leis formais. ${ }^{22} \mathrm{O}$ processo de constituiçąo destas leis nã்o deverá, em princípio, diferir do da constituição das essências. Tal como a partir da audição de um som constato que ele possui uma intensidade, uma qualidade, etc., ou seja, que ao conceito de som estão vinculados estes conceitos parciais não autónomos, e, por livre variação, que qualquer estado-de-coisas semelhante deverá conter idênticos conceitos parciais; assim também a análise de um juízo possível me permitirá descobrir os elementos que nele - seja qual for o estado-de-coisas julgado - pertencem à essência do juízo, ou às leis formais que regulam os todos os juízos possíveis.

\section{O "projeto transcendental" e a genealogia da lógica em experiência e juízo}

As idealidades da lógica e da matemática formais, tal como outros tipos de idealidade (essências, etc.), conservam um tipo de referência ao tempo diferente da que caracteriza os objetos reais, e que Husserl denomina All-Zeitlichkeit; nem a temporalidade, nem intemporalidade, mas sim omni-temporalidade. Na realidade, estas idealidades foram constituídas no tempo e no espaço, porém, valem, não para um momento em particular da série temporal, mas sim para todos eles. Compreendemos com mais facilidade as características próprias desta dimensão temporal se compararmos as idealidades lógico-matemáticas com obras como o Fausto de Goethe ou a Madonna da Capela Sistina, ${ }^{23}$ exemplos do que Husserl chama Kulturgegenständlichkeiten. Nenhuma destas duas obras constitui um género que subsumiria diverșas instanciações, que seriam os vários exemplares em livro ou diversas reproduções fotográficas. A legalidade que se exprime nos princípios da lógica e da matemática

${ }^{22}$ Experiência e Juizo, $\S 97$ c, p. 455. (Referimo-nos com frequência a esta obra pela sigla $E U$, que se reporta às iniciais do título em alemão. Utilizámos a edição da Editora Felix Meiner, referida na bibliografia final, que conserva a paginação das edições alemãs anteriores.)

$E U_{;} \& 65$, pp. 319-320. 
formal é do tipo que $E U$ chama "idealidade livre", ${ }^{24}$ quer dizer, caracterizada por uma relação neutra perante a realidade, de tal forma que ela é independente de qualquer realização, valendo "de uma vez por todas" e "para toda a gente". Assim, podemos dizer que o princípio de não-contradição seria válido mesmo que, por absurdo, nenhum juízo efetivo o respeitasse; tal como podemos afirmar que os princípios da ontologia formal valem para a ideia de objeto em geral, independentemente das características particulares que fazem de cada objeto um objeto pertencente a uma dada região, com a sua essência material própria.

Por conseguinte, carácter fáctico mundano destas idealidades, em resultado da intenção de verdade que anima o seu emprego para objetividades do nosso mundo real, bem como as condições fácticas que possibilitaram a sua descoberta, a história do círculo cultural onde ela se deu, etc., por outras palavras, a sua existência espacial e temporal secundária e a sua incorporação física em sinais escritos, não devem ser confundidas com o seu valor objetivo.

Husserl exprimira já a necessidade desta investigação no $\S 8$ de $F T L, 25$ ao afirmar que a temática da lógica possui um lado subjetivo que se dirige para a investigação das formas subjetivas profundas e ocultas nas quais a razão teórica origina as suas realizações superiores. O que existe de peculiar na objetividade própria das configurações ideais da lógica não dispensa uma investigação da atividade subjetiva que presidiu ao seu engendramento, uma vez a psique liberta de todas as conexões psicologistas que as Investigações Lógicas tinham já criticado.

É em resultado da sua própria natureza que a lógica formal possui um lado objetivo e um lado subjetivo. Dotada de uma orientação normativa, na medida em que estabelece as leis que regulam as operações subjetivas do conhecimento, é também a ciência das objetividades ideais de um sujeito orientado por um interesse de conhecimento. Daí que confiar o estudo deste sujeito a uma ciência de orientação objetiva, como é a psicologia empírica, constituísse um equívoco, uma vez que esta ciência, 'como qualquer ciência, aliás, é já uma realização subjetiva de uma comunidade de investigadores, orientados por um método particular. Este equívoco, denunciado no livro da Crise, só poderia ser ultrapassado graças ao desenvolvimento de uma ciência subjetiva das realizações subjetivas, capaz de explicitar as modalidades da vida intencional que originaram estas últimas. Esta ciência é a lógica transcendental, a ciência dos fundamentos da função normativa da lógica. ${ }^{26}$

${ }^{24}$ Ibid., p. 321.

${ }^{25}$ FTL, \& 8, Hua XVII, 38.

${ }^{26}$ Krisis, Hua VI, $149 ; \S 34$ c). Cf. André de Muralt, L'Idée de la Phénoménologie. L'Exemplarisme Husserlien, ed. cit., pp. 94-96. 
Esta ciência subjetiva da subjetividade comporta, segundo Husserl, uma dimensão genealógica, que explora o processo de constituição das objetividades lógicas pela subjetividade transcendental, a partir da' experiência. É o que anuncia Landgrebe, no $\S 13$ da "Introdução" a Experiência e Juizo, ao defender a existência de uma estrutura universal do juízo que se manifesta em todos os níveis do trabalho lógico, não apenas no nível superior em que o objeto é considerado como o sujeito de predicados possíveis, mas também, já, no nível inferior, em que o objeto deve ser considerado apenas como o substrato de um juízo possível e o julgar está em conexão com a experiência vital. Em qualquer destes níveis, a análise fenomenológica descobrirá uma mesma atividade da intencionalidade constituinte do Eu. Estas afirmações permitem-nos uma mais rigorosa delimitação do âmbito de uma investigação transcendental relativa ao tema "origem da lógica", mas delas parece também depreender-se um esbatimento das fronteiras entre a estética e a lógica, tal como Kant as delimitara. Uma investigação sobre a "origem da lógica" deverá proceder à clarificação dos conceitos lógicos fundamentais a partir de uma experiência sensível onde o "lógico" é já operante, elevando-se ao ponto de vista das realizações subjetivas da consciência, na qual se visa o conhecimentó de estados de coisas, que devem ser captados em juízos evidentes.

\subsection{Estética transcendental e lógica transcendental}

Estas últimas considerações remetem-nos para a problemática da estética transcendental. As referências de Husserl ao programa que esta disciplina seria chamada a cumprir são relativamente escassas e o próprio recurso a esta designação poderá não ser alheio a uma intenção polémica; com efeito, contra a tentativa neo-kantiana de absorver a estética pela lógica, Husserl, mesmo correndo o risco de gerar alguma confusão entre aquilo que propõe com esta designação e o que Kant entendia por ela, pretende mostrar que as estruturas lógicas superiores apenas são compreensíveis mediante uma análise dos três seguintes fatores: a associação, a estrutura horizontal da consciência e o tempo imanente. Eles possibilitam, não só que a experiência de cada um remeta para um único mundo, como também que um único mundo comum subjaza à experiência de todos.

Mas Husserl põe ainda em evidência que a nossa perceção dos objetos reais se faz já de acordo com uma generalidade típica que, por assim dizer, antecipa a síntese judicativa. Em Experiência e Juizo (se bem que no $\S 13$ da "Introdução", ou seja, naquela parte, justamente, em que a responsabilidade pela redação coube, como temos afirmado, a Landgrebe), fala-se, inclusivamente, de "juízo em sentido muito amplo", ou seja, de um juízo que não seria predicativo, no qual se realiza um trabalho de identificação que ainda não constituiu o seu substrato em objeto de um "dirigir-se para" temático, que o transformasse em suporte de determinações ou propriedades, que constituirão 
os predicados possíveis do nível lógico-categorial. Desta forma, nos limites inferiores da atividade cognitiva, está já operante um primeiro trabalho de constituição. ${ }^{27} \mathrm{O}$ facto de o olhar, por assim dizer, percorrer aquilo que é dado, tomando disso várias perspetivas que são unificadas numa consciência de identidade do objeto visto, significa que não nos encontramos já aqui num registo de pura passividade. Esta situa-se num nível ainda mais baixo, a saber, no nível da pura crença passiva no ser (que Husserl designa pelo termo Urdoxa), na qual o mundo é somente o mundo da "pura experiência" 28 e não se transformou ainda em tema da atividade intencional. É àquela atividade cognitiva de nível inferior, embora posterior a esta pura crença passiva, e que constitui por si só já uma realização subjetiva, que se poderá chamar um juízo ante predicativo.

Admitida, assim, a existência de um juízo antepredicativo, verifica-se que a sua função é dupla. Por um lado ele constitui a base a partir da qual se erigirá a atividade categorial; por outro - e este ponto, nem sempre devidamente salientado, é essencial -, ele orienta a atividade categorial presente, fornecendo-lhe o material sem a qual (tal como os conceitos sem intuição, de acordo com Kant) ela permaneceria uma atividade vazia. ${ }^{29}$ Em certas passagens de Experiência e Juizo Husserl levou a cabo análises pormenorizadas deste processo. Assim aconteceu, por exemplo, no $§ 24$. Nomeadamente, na análise do fenómeno de recobrimento parcial de uma intenção, quando um certo $\mathrm{p}$ é visto como propriedade de um $\mathrm{S}$ (antes ainda do surgimento da forma categorial "S é p"), numa síntese do tema principal da atenção (a saber, o próprio $\mathrm{S}$ ) e do tema ou dos temas secundários (um $\mathrm{p}$, ou vários p's).$^{30}$ Para tornar claro este processo, dever-se-á distinguir:

1. O facto do carácter parcial do recobrimento referido, uma vez que "p" não constitui a totalidade de "S";

2. A constituição de uma unidade de recobrimento ${ }^{31}$ na medida em que "p" pertence a "S".

${ }^{27}$ Sobre este assunto, cf. EU, pp. 60-62.

${ }^{28}$ Cf. FTL, Hua XVI, 256-257.

29 "Dieter Lohmar, "La genèse du jugement antéprédicatif", in Jean-François Courtine (dir.), Logique et Phénoménologie, Paris: Presses de l’École Normale Supérieur, 1996, pp. 217-238, p. 236.

${ }^{30} E U, \S 24$ b, pp. 128-129. A distinção entre tema principal e tema secundário (ou temas secundários) corresponde, aproximadamente, à distinção estabelecida por Aron Gurvitsch entre tema e campo temático. Aproveitamos, assim, a definição destes dois conceitos que é dada pelo autor (cf. Théorie du Champ de la Conscience, trad. M. Butor, Paris: Desclée de Brouwer, 1957, p. 12) para o nosso propósito na atual exposição: tema é aquilo em que se concentra, num momento dado, a atividade mental, o que ocupa o foco da sua atenção, ao passo que o campo temático é constituido pelos dados presentes concomitantemente com o tema e tendo com ele uma relação intríiseca.

${ }^{31}$ Husserl utiliza a expressão Deckungseinheit em EU, § 24 a), p. 127. 
A relação entre recobrimento parcial e unidade de recobrimento constitui o lugar de origem das primeiras categorias lógicas, como, por exemplo, as de sujeito e predicado. E embora destas e de outras categorias lógicas só se possa falar com propriedade no âmbito do juízo predicativo é na síntese pré-predicativa que se origina a totalidade das formas categoriais.

\subsection{O nivel antepredicativo e o mundo da vida}

A tematização do nível da experiência antepredicativa procura esclarecer a natureza das condições em que se funda a clareza e a evidência dos juízos. Suponhamos que alguém emite a asserção seguinte: "uma cor +1 $=3 " .{ }^{32}$ Diremos que tal juízo não tem sentido, não porque o resultado da operação de adição não seja aquele, mas sim porque os significados de "cor", "número" e "adição" não são compatíveis. Ora, será claro todo o juízo em que, independentemente do valor de verdade, os significados que ocupam os "lugares vazios" de sujeito, predicado nominal, predicado verbal (ou cópula), etc., forem compatíveis. ${ }^{33}$ No plano da apofântica formal, em que nos situávamos de início, apenas podíamos dizer que àqueles "lugares vazioș" teria de corresponder um substrato que as letras proposicionais, com os quais os designávamos, representariam simbolicamente. $\mathrm{O}$ acesso a estes substratos últimos não é da competência da lógica formal.

Suponhamos que alguém afirma: "Sp é q". A clareza deste juizo, por outras palavras, a sua verdade possível, repousa na prévia evidência da compatibilidade entre "S" e " $p$ ", ou seja, na possibilidade de o juízo "S é p". ser verdadeiro. Não nos deveremos deixar desorientar, uma vez mais, pelo carácter aparentemente trivial desta afirmação. É que entre a mera efetuação da possibilidade de reativar a experiência de uma compatibilidade (o que nem sempre é necessário fazer, como é óbvio) e a assunção dessa possibilidade como norma de validade vai uma distância considerável. Desta forma, a atividade que originariamente constituiu a unidade de sentido "Sp" e que, ao ser reativada e reproduzida, garanta a evidência do juízo "S é p", deverá valer não só para "Sp", mas também para o próprio "S". Reativamos e reproduzimos, agora, a experiência do substrato que lhe corresponde. A clareza só é compreensivel, em última instância, por recurso à experiência sensível, onde nos são dados, diríamos "desprovidos de sintaxe", os indivíduos que representamos simbolicamente por meio daquele "S". Como afirma FTL, objetividades categoriais

32 O exemplo é do próprio Husserl; cf. FTL, Hua XVII, 224.

${ }^{33}$ Que clareza e verdade (ou falsidade) pertencem a níveis de questionamento lógico diferentes, segundo Husserl, é assunto a que também já nos referimos anteriormente quando mencionámos os três niveis da apofântica formal. 
como são os juízos contêm em si, na qualidade de momentos constitutivos da génese do seu sentido, um certo tipo de historicidade, por via do qual remetem para um sentido originário e para o tipo de intencionalidade noemática que the corresponde. Assim, por exemplo, já vimos que o predicado nominalizado "vermelho", reenvia, do ponto de vista noético, para o trabalho de nominalização e, de um ponto de vista noemático, para a cor vermelha enquanto predicado de um juízo. ${ }^{34}$ Este plano em que se procura uma fundamentação última do juízo caracteriza a lógica filosófica, empenhada na descoberta das fontes subjetivas das suas configurações objetivas. ${ }^{35}$

A análise da perceção de uma criança - ou melhor, do modo como uma criança aprende a percecionar -, a que Husserl dedica algumas páginas, comprova o que estamos dizendo. ${ }^{36} \mathrm{~A}$ aprendizagem do ver não envolve qualquer tipo de atividade categorial, nem supõe a formulação explícita de quaisquer juízos, tal como o seu campo percetivo não comporta ainda propriamente objetos, tendo lugar no âmbito da síntese passiva. De igual forma, não encontramos ainda, aqui, lugar para distinguir entre o material de ordem sensível e a noese intencional. Justamente por não ser este o caso é que as análises genétiças levadas a cabo por Husserl não se limitam a esclarecer a génese das categorias lógicas, mas repercutem-se nas suas análises anteriores sobre a correlação noético-noemática e sobre a natureza dos atos doadores de sentido. Robert Sokolowski chamou a atenção para uma adenda, datada de 1928, ao $\S 88$ de Ideias-I, em que Husserl menciona explicitamente o facto de não existir uma dualidade entre as intenções e os dados hiléticos que contribuem para o processo de constituição de um sentido noemático concreto. ${ }^{37}$

Não pode também passar despercebida a semelhança (que se estende, inclusive, ao plano meramente lexical) entre o modo como é tematizada a problemática da Lebenswelt na Krisis e o modo como são conduzidas as investigações em torno da genealogia da lógica. Nos dois casos, trata-se, diz Husserl, de um regresso, um Rückgang. ${ }^{38} \mathrm{O}$ facto de tal regresso não ser motivado, nos

${ }^{4}$ FTL, § 85, p. 215.

$35 \mathrm{EU}$, pp. 159-160.

${ }^{36}$ Cf. Cartesianische Meditationen, Hua I, 112.

37 Cf. Robert Sokolowski, The Formation of Husserl's Concept of Constitution, ed. cit., p. 180. Cf. Hua III, 478. O que acabámos de dizer permitiria estabelecer uma aproximação entre a teoria husserliana da perceção e a Gestaltpsychologie. Também esta última sublinhou a existência de fatores internos de organização da atividade precetiva, que remetiam para a história sedimentada do sujeito que perceciona, ao contrário de Jean Piaget, que afirmava existirem fatores não percetivos que desempenhavam tal papel. Cf. Aron Gurwitsch, Théorie du Champ de la Conscience, ed. cit., p. 49.

${ }^{38}$ Poder-se-ia objetar que, em Experiência e Juizo, é Landgrebe e não Husserl que o diz, tanto mais que o aparecimento do conceito de Rückgang tem lugar nos $\$ \S 10$ e 11 da Introdução, 
dois casos, exatamente pelo mesmo tipo de interesse temático, não impede que reconheçamos profundas semelhanças entre eles. Poder-șe-á realizar a análise de um exemplo simples, no sentido de facilitar a compreensão dessas semelhanças. Suponhamos o juízo: "este cão é da raça rottweiler". A explicação da sua génese, tanto de um ponto de vista lógico-categorial, como do ponto de vista da sua inserção na situação concreta do mundo-da-vida, depara-se com os seguintes elementos comuns:

1. A identificação de um objeto (o cão) segundo um determinado universal, resultado do hábito contraído na perceção de indivíduos semelhantes designados por um nome comum; tal identificação remete para uma determinada situação biográfica de quem emite tal juízo, caracterizada por um stock disponível e partilhável de conhecimentos. ${ }^{39}$

2. A tipificação do sujeito do juízo (o mesmo cão) de acordo com certas estruturas particulares de relevância; ele não é especificado como "o meu cão" (embora possa ser o meu), nem como mero exemplar da espécie canina, nem como ser vivo em geral.

3. A consciência de que o predicado que, num determinado momento, serve para identificar um sujeito (o predicado "rottweiler", no exemplo que foi dado mais acima), não é o único que lhe convém. Ou seja, que "S" não é apenas "p", mas é também (ou pode ser) "q", "r", "s", etc.

Aprofundemos um pouco esta análise, recorrendo a uma linguagem que já não é a de Husserl. ${ }^{40}$ A proposição "este cão é da raça rottweiller", logicamente analisada, significa duas coisas: 1 ) que um indivíduo $X$ recebe o predicado $C$ (ser um cão); 2) que $X$ (que é C) $\varepsilon \mathrm{R}$ (a raça dos cães rottweiller). Ora, a proposição "este cão é da raça rottweiller", enquanto simples enunciado empírico de observação - verdadeiro ou falso, o que para o caso não importa -, recebe,

cuja redação é de Landgrebe e não de Husserl. Não deixa, contudo, de ser verdade que Landgrebe baseou o seu trabalho de redação em textos que o próprio Husserl lhe facultou e que o aparecimento do termo não acontece apenas na Introdução. Mais importante é determinar a que é que efetivamente se regressa. Por outro lado, que os interesses de ordem estritamente cognitiva sejam distintos dos de ordem exclusivamente prática ou valorativa, é reconhecido por Husserl no $\S 48$ de $E U$ (ed. cit., pp. 235-239).

39 Alfred Schutz evidenciou bem a necessidade de se ter em conta um tal stock para explicar juizos desta natureza. O stock de conhecimentos disponíveis para cada indivíduo deverá ser tido em conta em qualquer análise das relações intersubjetivas que caracterizam o mundo da vida. (Cf. "Some structures of the life-world", in Collected Papers, III, The Hague: Martinus Nijhoff, 1975, pp. 116-132, pp. 124-125.)

${ }^{40}$ A única diferença significativa é que não faremos uso da fórmula "S é p", herdada da lógica clássica e que consideramos demasiado restritiva. Em tudo o resto, julgamos permanecer fiéis ao pensamento de Husserl. 
no mundo-da-vida, um sentido que é anterior ao que lhe virá a ser conferido pela análise lógica; ele traduz o meu conhecimento maior ou menor das raças de cães, o meu gosto por esta raça particular (ou o meu receio dela...), etc. O que está em causa nestas análises de Husserl é a verificação da existência de um termo intermédio entre a perceção e o juízo em sentido estrito, algo que está para lá da mera doação de um objeto e se constitui como uma aquisição permanente do sujeito que experimenta. ${ }^{41} \mathrm{~A}$ transformação deste sedimento, efetuada pela atividade judicativa, dará origem ao juízo.

\subsection{A legalidade própria do mundo da vida}

O mundo da vida caracteriza-se por possuir uma estrutura tal que, não só garante a possibilidade de uma perceção concordante dos objetos que dele fazem parte, como também garante a possibilidade de o transformar em tema de uma ciência própria. Graças a essa estrutura invariante, posso, por exemplo, identificar o mundo das minhas recordações com o mundo em que agora vivo, mesmo que ele tenha sofrido diversas transformações; ou identificar o mundo presentificado pelas recordações de uma outra pessoa com o mundo que eu próprio presentifico quando recordo a minha vida passada; ou, tendo eventualmente mudado de lugar de residência, reconhecer que o mundo em que vivo agora e aquele em que vivi outrora são apenas locais diferentes do mesmo planeta que não deixei nem poderei deixar de habitar.

Esta estrutura é o que, na Krisis, Husserl chamará a tipicalidade específica do mundo da vida. A partir dela, é possível mostrar como, na base deste mundo da vida intersubjetivo, se construíram os mundos objectivos das ciências, como formações de nível superior, em resultado de operações idealizadoras. No mundo da vida, reside ainda o facto de que o que Husserl chama, no Anexo II da Krisis $^{42}$ a representação experiencial de cada sujeito ser concordante com as representações experienciais dos outros sujeitos, gerando, assim; a expectativa de uma coincidência entre as respetivas representações, mesmo que apenas nos limites do que Husserl designa como uma "tipologia vaga". Da mesma forma, no âmbito do mundo da vida, o que para cada sujeito vale como existente deverá valer como existente para todos os sujeitos. Chegamos ao ponto onde a problemática destas duas obras, tendo cada uma delas arrancado de um ponto de partida diferente, se toca. O método regressivo das duas, de que falávamos quase no início, conduziu a uma mesma constatação. Esta coincidência nos resultados será a comprovação de que a legalidade própria

41 Cf. Dieter Lohmar, op. cit., p. 158.

42 Krisis, Hua VI, 357. 
dos princípios da lógiça e da matemática formal se funda numa estrutura da mundo da vida que institui uma comunidade de entendimento possível entre todos os seres racionais.

\section{Referências}

BACHelard, Suzanne (1957). La Logique de Husserl. Paris: PUF.

BACHELARD, Suzanne (1974). Logique husserlienne et sémantique. In: Vérité et Vérification / Wahrheit und Verification, Akten des vierten internationales Kongresses für Phänomenologie. Den Haag: Martinus Nijhoff, pp. 117-131.

Gurvitsch, Aron (1957). Théorie du Champ de la Conscience. Trad. M. Butor. Paris: Desclée de Brouwer.

HaRtimo, Mirja (2006). Logic as a Universal Medium or Logic as a Calculus? Husserl and the Presuppositions of the "Ultimate Presupposition of Twentieth Century Philosophy". The Southern Journal of Philosophy, XLIV (2006): 569-580.

HEFFERNAN, George (1989). Isagoge in die phänomenologische Apophantik. Dordrecht/ Boston/London: Kluwer Academic Press.

HusserL, Edmund (1948). Erfahrung und Urteil. Hamburg: Classen und Goverts. (Reimp. Hamburg: Felix Meiner Verlag, 1999, 7. a ed.)

HuSsERL, Edmund (1962). Die Krisis der europäischen Wissenschaften und die transzendentale Phänomenologie, Husserliana, Band VI. Den Haag: Martinus Nijhoff.

HusserL, Edmund (1974). Formale und transzendentale Logik, Husserliana, Band XVII. Den Haag: Martinus Nijhoff.

Livingston, Paul (2002). Husserl and Schlick on the logical form of Experience. Synthese, 132 (2002): 239-272.

LoHMar, Dieter (1996). La genèse du jugement antéprédicatif. In: Jean-François Courtine (dir.), Logique et Phénoménologie. Paris: Presses de l'École Normale Supérieur, pp. 217-238.

LOHMAR, Dieter (2000). Edmund Husserls >Formale und transzendentale Logik<. Darmstadt: Wissenschaftsliche Buchgesellschaft.

Mohanty, J. N. (1976). Edmund Husserl's Theory of Meaning. The Hague: Martinus Nijhoff.

Morujão, Carlos (2002-2003). Fenomenologia e psicologia descritiva. (A propósito de algumas relações entre a fenomenologia, a lógia e a matemática.). Phainomenon, 5-6 (2002-2003): 87-98.

Muralt, Andrée de (1958). L'Idée de la Phénoménologie. L'Exemplarisme Husserlien. Paris: PUF.

Olaru, Bogdan (2002). Edmund Husserls "Formale und transzendentale Logik. Bemerkungen zu den Kapiteln 2 und 3 des II Abschnittes". Noesis, XXVII (2002): 57-62. 
ORTH, Ernst Wolfgang (1999). Edmund Husserls > Krisis der europäischen Wissenschaften und die transzendentale Phänomenologie<. Darmstadt: Wissenschaftliche Buchgesellschaft.

Patras, Frédéric (1996). Sur la phénoménologie de la connaissance mathématique. In: Jean-François Courtine (dir.), Phénoménologie et Logique. Paris: Presses de l'École Nrmale Supérieur, pp. 109-121.

ReINER, Hans \& Schumann, Karl (1989). Ein Protokoll aus Husserls Logikseminar vom Winter 1925. Husserl Studies, 6 (1989): 199-204.

Rota, Gian-Carlo (1973). Edmund Husserl and the reform of Logic. In: David Carr \& Edward S. Casey, Explorations in Phenomenology. The Hague: Martinus Nijhoff, pp. 298-305.

Srvák, Jozef (2006). De l'idée de la forme phénoménologique. Analecta Husserliana, 90 (2006): 431-438.

Sokolowski, Robert (1970). The Formation of Husserl's Concept of Constitution. The Hague: Martinus Nijhoff.

Schutz, Alfred (1975). Some structures of the life-world. Collected Papers, III. The Hague: Martinus Nijhoff.

Tiro, Johanna Maria (1990). Logic in the Husserlian Context. Evanston (Ill.): Northwestern University Press.

\begin{abstract}
This paper is divided into three parts. The first part addresses the main tenets of Husserl's conception of formal logic, its different levels and its relationship with formal mathematics and formal ontology. It will, therefore, undertake a delimitation of the logical domain, in its autonomy, taking as its point of departure the presentation Husserl makes of this subject in his works of maturity, particularly in Formale und transzendentale Logik. The second part shows why, for phenomenology, the analysis of objective logical configurations has to be completed by a subjective analysis of the intentional achievements in which these configurations have their genesis. In other words, we will try to ground such an autonomy in the very nature of logical reason. Finally, the third and last part, following the text of the first two sections of Erfahrung und Urteil, adresses the roots of the logical-categorical activity in the ante-predicative passive experience.
\end{abstract}

